\title{
Existential Experience of Absurd: Its Mental Background in Modern Culture
}

\author{
Svetlana Rudanovskaya \\ Department of Social Philosophy \\ Faculty of Humanities and Social Sciences \\ Peoples' Friendship University of Russia (RUDN University) \\ 6 Miklukho-Maklaya Street \\ Moscow, Russian Federation 117198 \\ E-mail: rudsv@live.ru
}

\begin{abstract}
The paper gives an analytical review of various implications and premises of absurd as existential experience in the light of literary and philosophical texts that contribute to the cultural style of the XXth century. Experience of absurd is regarded as a result of hermeneutic incompatibility of different mindsets as well as an indispensable element of certain frames of mind emphasizing the semantic emptiness of natural language and questioning the status of human being in the universe. The main emphasis is made on absurd as a challenge to human thought that brings absurd to light and makes attempts to comprehend the incomprehensible.
\end{abstract}

Keywords—absurd; existential experience; meaning; crisis of language; existentialism; surrealism

\section{INTRODUCTION}

Absurd is something which resists definitions. If absurd is detected, there is a natural desire to get rid of it: to eliminate it as a nuisance or understand it as a part of a meaningful whole. Absurd appears as a name to stress some impossible, illogical state of affairs, and then be dismissed, give place to reasonable statements.

Discussing absurd is somewhat strange, as it stands for a cul-de-sac, where no intelligible design is possible. However the idea of absurd arises precisely within an intelligible attitude towards the world which lets persons to distinguish sense from nonsense, cosmos from chaos, discourse from delirium. On the one hand, absurd is something that threatens a comprehensive picture of the world, on the other - as our assessment of something out of the order — protects the mind from twists of imagination that are opposite to sensible judgments or a reasonable way of life (such as "twice two makes five is sometimes a very charming thing too" (F. Dostoevsky).

The essence of absurd doesn't amount entirely to something irrational, unusual and confusing, which is highlighted by human thought and in turn sets it off. When the statement $\mathrm{A}$ is considered absurd, $\mathrm{A}$ is not just nonsense, which has no relation to the sense of meaning, but nonsense which pretends to be meaningful. For example, there is no absurd in listing various wonderful creatures: from those who "belong to the emperor" to those, who "have just broken the flower vase" or who "at a distance resemble flies" (Chinese encyclopedia described in one of J. L. Borges' short stories). The absurd manifests itself as soon as this arbitrary enumeration is supposed to represent a certain order, a classification (the Chinese encyclopedia described in one of Borges's short stories) [1].

The same goes for Zen koans. Their seeming absurdity is not so much derived from their inconsistency, the deliberate lack of logic, but from the fact that it is hard to believe that this is a kind of wisdom. If the same words were pronounced by a child, a fool or an insane, that is a human being who was not taken seriously, the conflict between sense and nonsense would have not been so visible.

From the point of view of a reasonable observer absurd is a simulacrum of meaning, "a pretender" that has no right to exist (J. Deleuze). But it is necessary to take into account that simulacrum is "nothing" which pretends to be something and which makes everybody to forget about this "nothingness". Simulacrum has a hypnotic effect as it smoothly replaces reality, without provoking questions about authentic and inauthentic things.

Absurd, on the contrary, is "something" that actualize the feeling of "nothing". This absurd neither substitutes the meaningful order nor plays with appearances. It wedges itself in the order, breaks the cognitive peace, brings confusion by insulting a sense of measure, norm, proper action, in short - the common sense. That is why absurd is usually accompanied with an exclamatory tone, above all, the tone of indignation.

In modern culture, absurd is not only a reverse of meaning, but also signifies quests for and experiments with new strata of human experience, fraught with new meanings.

\section{EXPERIENCE OF OTHER MINDSET}

Our knowing something as absurd first of all depends on the context, that is on the situation where one system of meanings (or one mindset) overlaps another, intrudes into the foreign territory with its postulates, rules, modes of perception [2]. In that case those postulates seem to be 
ridiculous, artificial, abstract, "not of this world", inconsistent with current realities (or with common views). Representing an alternative meaning, absurd phenomenon is rather unknown and unnoticed by reason than opposite to it. According to a Russian philosopher of culture G. Pomeranc, "behind a given opposition reason-absurd there are sometimes two reasons, each of them considers its opponent nonsensical, ridicule" [3]. Spontaneous wisdom of Zen sages stays hermeneutically impenetrable for western rationality. A "polyphonic" novel by F. Dostoevsky would be "conglomerate of heterogeneous materials and incompatible principles of style" (M. Bakhtin) within classical point of view [4]. Traditional metaphysics would hardly accept postmodernism with its "playful" attitudes towards the truth or towards human nature [5].

At the same time in modern culture there are deliberate attempts to overcome the routine of day-to-day experience and discover authentic reality by stating another point of view, an alternative order, some abnormal speech. For example, in "Notes from the Underground" F. Dostoevsky depicts a person who exposes everything to "chemical disintegration", suffers from the lack of certainty, inability to create a finished work of thought. He is an exact antipode of successful sophist or well-off citizen who speaks out of selfsatisfaction without caring about the ontological dimension of reality. This speech may be convincing, luring and humanly attractive. Sophistic twists are not true from the philosophical point of view, but at the same time they cannot be called absurd from the common point of view. The only thing that can be noticed is that they are functional, useful in obtaining the intended effects (as simulacrum is)

"The underground" represents the opposite of normal communication, a world where nothing can be proved or disproved finally. While sophistry is a gift of speech which lets humans to be successful in talking everybody in and out of any proposition, the underground involves selfconsumption by inward gnawing which enforces the thought to shilly-shallying, suffer from indefiniteness. Nevertheless a speech of an underground person has its own credibility as sophistry does. It is absurd because it embodies an alternative view of the world (taking the stand of a mouseman) and enters into an open dispute with a natural (or practical) mindset: "persons of strong nerves", a bull-man, who "simply dashes straight for his object with its horns down, and nothing but a wall will stop him" give way to people with a broken nervous system, a man-mouse, whose lot is "to dismiss all that with a wave of its paw, and, with a smile of assumed contempt in which it does not even itself believe, creep ignominiously into its mouse-hole". "Cold, malignant and, above all, everlasting spite" is contraposed to a normal immediate reactions of a healthy creature (indignation, rage, force of hands etc.) [6].

The underground person signifies a deviation from socially accepted way of discourse with its credible purposes and embedded utility, his speech addresses nobody particular and leads nowhere. At the same time it is characterized by "a logic of dispute" (G. Pomeranc) which is the main cause of all logical, ethical, aesthetical inversions, all sayings out of spite, presented in the text. That logic of dispute is at the heart of eternal conflicts between "the fathers and the sons", the new and the old, established stereotypes and "abnormal" mindsets that arise both on the grounds and despite traditional concepts and rules. This logic of dispute exists in postmodernism which replaces the metaphysical experience of solid grounds with the textual experience of "the groundless", multiple interpretations, guesses, equally possible and equally meaningful in the circulation of "chaosmos" (J. Deleuze): everything may be discovered with no real discovery at all [7].

A drastic break with tradition is a key feature of philosophical and literary quests during the end of the XIXth - a first half of the XXth centuries. The dissociation from "the precepts of ancestors" implies an attempt to reveal a new semantic spaces in the spheres where "nothing except hiatus, gap, lack of any position can exist" [8]. During the quests like these "the absurd of existence", "the meaning as absurd" become themes of existential works by S. Kierkegaard (Fear and Trembling), Lev Shestov (Apotheosis of Groundlessness), J-P. Sartre (Nausea), A.Camus (The Stranger, Caligula, The Myth of Sisyphus), while the absurdist speech is transformed into a stylistic technique in surrealism, the Oberiuts, Theatre of Absurd.

\section{CRISIS OF LANGUAGE AND EXPERIENCE OF EMPTINESS}

In the XXth century absurd implies more than the other mentality. The existential experience of absurd constitutes the worldview of thinking person in Western countries. First of all it is due to the phenomenon of the first half of the XX century which is known as "the crisis of language" which means that common language is inadequate, misleading in describing reality.

The bottom line of this crisis is that there are words, concepts, ideals, but they have nothing to do with what people really think and feel. According to one of J. Cortasar' literary characters: "I am again among calming notions: a worthless doll, a great novel, a heroic death. I line them up, from least to greatest: doll, novel, heroism. I think about the orders of values so well explored by Ortega, by Scheler: aesthetics, ethics, religion. Religion, aesthetics, ethics. Ethics, religion, aesthetics. Doll, novel. Death, doll. La Maga's tongue tickles me. Rocamadour, ethics, doll, Maga. Tongue, tickle, ethics" [9]. Values and ideals turn into empty words. They remind of themselves only by some psychological bothering they induce. The lofty words are easy to pronounce without any further consequences and easy to forget as they are abstracted from real life.

The idea that social and metaphysical experience of the past has been exhausted lets philosophers and artists be aware of drastic distance between words and things, thoughts and reality. In this situation some of the thinkers apply to phenomenological reduction which is supposed to help them bracket all cultural and day-to-day concepts in order to have the original encounter with things as they are; analytical philosophers explore operations which is supposed to free human minds from captivity of illusory problems engendered by "bad grammar"; representatives of semiotics analyze 
natural language revealing its false naturalness. All these strategies aims at elaborating new rules of rational description of reality instead of the old ones.

At the same time this crisis of language leads to overall disappointment in cultural constructs, artificial and outlived. The only reasonable way of coping with this situation is to disclose and reject them, struggle with the hidden emptiness of signs, feelings and concepts in the spheres of day-to-day speech, social sciences and metaphysical studies. This mentality initiates the antagonism between humans and the familiar, but deceptive world.

The antagonism with empty appearances in culture and human behaviour may be analyzed in two perspectives: surrealistic and existential. In surrealism this rebellion is aimed at destruction of language and expressed in acts of violence towards artifacts associated with high values: for example, using a Rembrandt's picture as an ironing board [10]. This is a rebellion which draws strength in scandals, Dionysian longing for total confusion: "I want to drown the sky in the sea, to infuse ugliness with beauty, to wring a laugh from pain. - There's good and bad, high and low, justice and injustice. - And I'm resolved to change them ... I shall make this age of ours a kingly gift — the gift of equality. And when all is leveled out, when the impossible has come to earth and the moon is in my hands - then, perhaps, I shall be transfigured and the world renewed; then men will die no more and at last be happy" [11]. These destructive intentions may not change life, but their key purpose is to change the perception of it, enlarge horizons of the possible by ignoring what is impossible.

From a surrealist's point of view it is indispensable to get rid of languid feelings, mediocrity of life built on beautiful (but empty) words. And this freedom is possible in reading, writing or involving in a theatrical action. According to the author of "theatre of cruelty" A. Artaud, a theatre should horrify, destruct the protective mechanisms of culture, dethroned the reality of everyday life, shake the lethargy of human existence. The theatre rushing into life like the plague is equated with apocalyptic force, which opens up boils, "purifies", vitalizes the perception of reality through the kind of catharsis - the experience of shock [12].

Existential authors also strive to make changes in human thought and perception. However if surrealistic rebellion against absurd reality is directed at blurring out distinctions between reality and dreaming (nightmare), existentialists' destruction of language is always secondary. Characters of existential stories are difficult to distinct from men in the street (S. Kierkegaard' knight of faith, A. Camus' "stranger"), ordinary laborers (A. Camus' Sisyphus, J.-P. Sartre' Roquentin). Unlike surrealists they are realists, aware of the ultimate limits of reality, its gravitational forces. Unlike ordinary laymen, they are outsiders who are estranged from their environment do not identify themselves with it.

Surrealists are anarchists in the sphere of aesthetics: they ignore the established order, exploring undiscovered spheres of culture and human mind. Existential authors are rather stoics, their goal is not "feast in time of plague", but being themselves despite the semantic emptiness of existing guiding lines, setting their hope for meaning against the meaningless world. Existential experience is determined by "moral inquisitions" (M. Bakhtin), paradoxical combination of self-destruction and self-assertion. "I suffer, therefore I exist" (N. Berdyaev); I experience nausea - therefore I exist (J.-P. Sartre); I rebel against inhuman world, therefore I exist (A. Camus).

Surrealistic rebellion is directly connected with "language crisis" and penetrated with hatred to "dead signs", spiritless words and things. Surrealistic experiments are supposed to shatter the fixed linguistic structures, give the word to the swirling stream of the unconscious, freeing it from the press of cultural norms and established dichotomies (including the dichotomy between meaning and absurdity). In contrast, existential philosophy, due to its status of "philosophia perenis" (N. Abbagnano), represents neverending problematic nature of human existence. While surrealism destructs all systematic ideas of rational and ethical thinking, existentialism destructs everything but one thing - the ultimate awareness of absurd.

\section{Human Existence as Problematic}

Absurd experience appears in existential philosophy within its quests for authenticity in life and style. Some existential philosophers use confessionary style for their work ("I wish to shout out to the world what I've heard inside" N. Berdyaev). Others use the prose of newspaper report, very precise descriptions of the facts. In any case the feeling of absurd follows a style of writing which lays bare the abandonment and insecurity of human existence, without usual consolations and hopes.

The world in this case is experienced as hermeneutically impenetrable, indifferent to human searches and troubles. The experience is painful, first of all because human demand for akin being (reasonable, sympathizing, saving) seems to be rejected by indifferent reality, but at the same time is realized as distinct and unique in the universe. Though within existential experience a person apprehends that this demand may be in vain, this very apprehension encourages one to be against that state of affairs and keep "longing for the lost paradise", going on with one's clear awareness of one's solitude in the world. Disagreement with inhuman milieu without compromises enables a person to return to $\mathrm{him} /$ herself, that is to the state of the utmost selfconsciousness in the face of meaningless outward reality [13].

Existential authors place their characters in desperate situations to find out that within those situations a human existence may be more intensive, thought-out, than nomadic life with open horizons or rhizome-like tracks of movements. In existential situations the experience of death is combined with creative ecstasy, desperation - with a pleasure from show, awareness of one's own insignificance - with awareness of one's own greatness: "To a man devoid of blinders, there is no finer sight than that of the intelligence at grips with a reality that transcends it. The sight of human pride is unequaled" [14].

But with all those peripetei as embedded in human search and challenges from indifferent world, the indifference of 
this world is being asserted with amazing persistence, if not with metaphysical stubbornness: "to understand it all, to recognize it all, all the impossibilities and the stone wall" and "not to be reconciled to one of those impossibilities and stone walls if it disgusts you to be reconciled to it" (F. Dostoevsky), make sure that "the desired is impossible" (S. Kierkegaard), insist on "an impossible transparency" of being (A. Camus). In the stubbornness there are no compromises, and no intermediary links between binary oppositions.

The experience of absurd in existential philosophy sometimes approximates to big generalizations, criticized by existential authors in rationalistic philosophical systems. This generalization is especially noticeable in "The Myth of Sisyphus" by A. Camus. Those who claim to be realists and those who seem to be escapists, those who strive to be themselves and those who strive to be somebody else, those who break logics and those who wish to be logical till the end, comedians, tragedians and aesthetes - all of them become characters who represent the idea of absurd existence in an essay with absurd-like message: "Let me repeat. None of all this has any real meaning. On the way to the liberty, there is still a progress to be made" [15]. By designating everything, the absurd ceases to mean what it does in the language of culture.

We may also ask what will happen with the experience of absurd, if it is prolonged in space and time as A. Camus suggests: "Living is keeping the absurd alive. Keeping it alive is, above all, contemplating it" [16]. Perhaps this approach prevents one to see or feel the real absurd that reveals itself in an event which should not have happened and nevertheless happened, despite all the reasonable arguments or intuitive confidence in the future. Perhaps a question - whether life is or not worth living - is somewhat out of tune, because it reduces a vast variety of existence to an abstract idea, a subject of final assessment.

At the same time a question concerning the meaning of life (implying the possibility of meaningless existence) is a question humans never stop to ask while trying to perceive their lives as a significant whole, in search of truth agreeable with their reason and feelings. This question is connected a great deal with other questions: what is the status of human reason with all its purposes, hopes and longings in the universe. Perhaps human consciousness arises due to awareness of absurd, or may be, as a Soviet historian B. Porshnev puts it, due to the fact that it "created stable absurdities" [17]. Anyway the questions existential philosophers ask reveals some initial and universal experience of both being human and being estranged from the surrounding world.

\section{CONCLUSION}

Absurd experience in XIX-XX centuries are partly derived from cognitive bewilderment of a reasonable observer, while encountering other way of thinking, as well as from deliberate experiments with alternative views. But primarily absurd experience arises out of the questions about familiar reality, ordinary language and daily schedule that turn out to be unsatisfactory for inquisitive mind. As one of $\mathrm{J}$ Cortazar's characters says: "The absurdity is that it doesn't look like an absurdity. The absurdity is that you go out in the morning and find a bottle of milk on the doorstep and you are at piece because the same thing happened to you yesterday and will happen again tomorrow. It's this stagnation, this so be it, this suspicious lack of exceptions" [18].

It is existential questions as well as rebellious zest accompanied these questions that break these peaceful appearances and bring idea and feelings of absurd to light. Sometimes this idea is introduced from the position of superior judge, prophet or titan shouldering all the burdens of life. Sometimes the idea is inseparable from a certain amount of self-irony which deflates one's ego and makes one get rid of too high opinion of one's virtues and sins, delusion of grandeur and "mania for spiritual possession" (J. Cortazar). The very suggestion that "man, the ephemeral inhabitant of an insignificant planet, with all his pain and all his striving is but a jest in an eternal mind" [19] does not so much undermine the meanings of human culture, as challenges the human thought in search of ways to overcome one's own fundamental incomprehension.

\section{REFERENCES}

[1] Borges J.L. John Wilkins' Analytical Language. Translated from Spanish by E. Lusenko // Borges J.L. Collected works in 3 volumes. V.2. Riga: "Polyaris", 1994. P.85-88.

[2] Bondar O. On the Question of the Interreligious Grounds of the Global World // Advances in Social Science, Education and Humanities Research. 3rd International Conference on Contemporary Education, Social Sciences and Humanities (ICCESSH 2018). - Paris: Atlantis Press, 2018 Vol.233.P.1460-1463.

[3] Pomeranc G. Language of absurd // Pomeranc G. "Out of Trance". M. Yurist, 1995. P. 439.

[4] Bakhtin M. Problems of Dostoevsky's Poetics.M.: “Alconost”, 1994 P.8.

[5] Tagirov F. V. Sexuality and its preferences: between binary and plural logic // Proceedings of the 2016 International Conference on Contemporary Education, Social Sciences and Humanities. SaintPetersburg, June, 2016. Atlantis Press, Paris, 2016. P. 650-656.

[6] Dostoevsky F. M. Notes from the Underground // Dostoevsky F. M. Collected works in 15th volumes. V.4. L.: "Nauka", 1989.

[7] Deleuze G. The Logic of Sense. Translated from French by Ya. Svirskoy.M.: "Raritet", Ekaterinburg: "Delovaya kniga", 1998. P. 342-343.

[8] Podoroga V. Expression and Meaning. M.: Ad Marginem, 1995. P.143.

[9] Cortazar J. Hopscotch. Translated from Spanish by L. Sinyanskaya. SPb: Azbuka, 2000. P.30., Cortazar J. Hopscotch Translated from Spanish by G. Rabassa. N.Y: Pantheon Books, 2014 (Kindle Edition).

[10] Mankovskaya N. Aesthetics of Postmodernism. SPb.: Aleteiya, 2000.

[11] Camus A. Caligula Translated from French by Yu. Ginsburg // Camus A. Collected works in 5 volumes. V.1. Kharkov: Folio, 1998. P.226, Camus A. Caligula and Three Other Plays. Translated from French by S. Gilbert, J. O'Brien. N.Y.: Vintage Books, 2012 (Kindle Edition).

[12] Artaud A. The Theatre and Its Double. Translated from French by S. Isaev. M.: Martis, 1993.

[13] Camus A. The Myth of Sisyphus. Translated from French by S. Velikovsky // Camus A. Collected works in 5 volumes. V.2. Kharkov: Folio, 1998. P. 47., Camus A. The Myth of Sisyphus. Translated by J. O'Brien. Penguin, 2013 (Kindle Edition) 
[14] Camus A. The Myth of Sisyphus. Translated from French by S. Velikovsky // Camus A. Collected works in 5 volumes. V.2. Kharkov: Folio, 1998. P. 49., Camus A. The Myth of Sisyphus. Translated by J. O'Brien. Penguin, 2013 (Kindle Edition)

[15] Camus A. The Myth of Sisyphus. Translated from French by S. Velikovsky // Camus A. Collected works in 5 volumes. V.2. Kharkov: Folio, 1998. C.27., Camus A. The Myth of Sisyphus. Translated by J. O'Brien. Penguin, 2013 (Kindle Edition)

[16] Camus A. The Myth of Sisyphus. Translated from French by S. Velikovsky // Camus A. Collected works in 5 volumes. V.2. Kharkov: Folio, 1998. C. 49., Camus A. The Myth of Sisyphus. Translated by J. O'Brien. Penguin, 2013 (Kindle Edition)

[17] Porshnev B. About the Beginning of Human History (problems of paleopsychology). M.: "Mysl", 1974.

[18] Cortazar J. Hopscotch. Translated from Spanish by L. Sinyanskaya. SPb.: Amfora, 2000. P. 191., Cortazar J. Hopscotch Translated from Spanish by Gregory Rabassa. N.Y: Pantheon Books, 2014 (Kindle Edition).

[19] Maugham W. S. Cakes and Ale. N.Y: Vintage Digital, 2010 (Kindle Edition) . 